Article

\title{
Few-Layered $\mathrm{MoS}_{2}$ Nanoparticles Covering Anatase $\mathrm{TiO}_{2}$ Nanosheets: Comparison between Ex Situ and In Situ Synthesis Approaches
}

\author{
Rosangela Santalucia (D), Tiziano Vacca, Federico Cesano $\left(\mathbb{D}\right.$, Gianmario Martra ${ }^{+} \mathbb{D}$, Francesco Pellegrino $\mathbb{D}$ \\ and Domenica Scarano *
}

Citation: Santalucia, R.; Vacca, T.

Cesano, F.; Martra, G.; Pellegrino, F.;

Scarano, D. Few-Layered $\mathrm{MoS}_{2}$

Nanoparticles Covering Anatase $\mathrm{TiO}_{2}$ Nanosheets: Comparison between Ex Situ and In Situ Synthesis

Approaches. Appl. Sci. 2021, 11, 143. https://dx.doi.org/10.3390/app1101 0143

Received: 20 November 2020 Accepted: 22 December 2020

Published: 25 December 2020

Publisher's Note: MDPI stays neutral with regard to jurisdictional claims in published maps and institutional affiliations.

Copyright: (c) 2020 by the authors. Licensee MDPI, Basel, Switzerland. This article is an open access article distributed under the terms and conditions of the Creative Commons Attribution (CC BY) license (https: / / creativecommons.org/ licenses/by/4.0/).
Department of Chemistry, NIS (Nanostructured Interfaces and Surfaces) Interdepartmental Centre and INSTM Centro di Riferimento, University of Torino, Via P. Giuria, 7, 10125 Torino, Italy; rosangela.santalucia@unito.it (R.S.); tiziano.vacca@edu.unito.it (T.V.); federico.cesano@unito.it (F.C.); francesco.pellegrino@unito.it (F.P.)

* Correspondence: domenica.scarano@unito.it; Tel.: +39-011-6707834

+ Dedicated to the memory of Gianmario Martra.

Abstract: $\mathrm{MoS}_{2} / \mathrm{TiO}_{2}$ nanostructures made of $\mathrm{MoS}_{2}$ nanoparticles covering $\mathrm{TiO}_{2}$ nanosheets have been synthesized, either via ex situ or in situ approaches. The morphology and structure of the $\mathrm{MoS}_{2} / \mathrm{TiO}_{2}$ hybrid nanostructures have been investigated and imaged by means of $\mathrm{X}$-ray diffraction (XRD) analysis and high-resolution transmission electron microscopy (HRTEM), while the vibrational and optical properties have been investigated by Raman, Fourier-transform infrared (FTIR), and UV-visible (UV-vis) spectroscopies. Different stacking levels and $\mathrm{MoS}_{2}$ nanosheets distribution on $\mathrm{TiO}_{2}$ nanosheets have been carefully evaluated from HRTEM images. Surface sites on the main exposed faces of both materials have been established by means of in situ FTIR spectra of CO probe molecule adsorption. The results of the ex situ and in situ approaches are compared to underline the role of the synthesis processes affecting the morphology and structure of $\mathrm{MoS}_{2}$ nanosheets, such as curvature, surface defects, and stacking order. It will be shown that as a result of the in situ approach, the reactivity of the $\mathrm{TiO}_{2}$ nanosheets and hence, in turn, the $\mathrm{MoS}_{2}-\mathrm{TiO}_{2}$ nanosheets interaction are modified.

Keywords: heterostructures; $\mathrm{TiO}_{2}$ nanosheets; few layers $\mathrm{MoS}_{2} / \mathrm{TiO}_{2}$; ex situ and in situ approaches; FTIR; Raman; UV-vis; XRD; HRTEM

\section{Introduction}

Heterostructures of different dimensionality have been investigated in the past because of their novel properties and challenging applications, including clean energy and new energy-related technologies, photocatalysis [1,2], electrocatalysis [3], solar cells [4], energy conversion and storage [1,5], up to research studies in biomedical fields [6-8]. In particular, since the discovery of graphene, $2 \mathrm{D}$ materials have attracted considerable attention due to their unique physical and chemical properties. Because of this, many efforts have been focused on the combination of two-dimensional layered materials (2DLMs) with zerodimensional ones (0D), such as plasmonic nanoparticles and quantum dots, and with monodimensional (1D) nanostructures, such as nanowires and nanoribbons, thus introducing a new way of nanoscale material integration and enabling the development of many extraordinary electronic devices. In this regard, 2D-2D van der Waals heterostructures made of distinct 2DLMs and superlattices [8] play a considerable role in controlling and manipulating the generation, confinement, and transport of charge carriers, excitons, photons, and phonons within the atomic interfaces, thus giving chances for the design of unique and challenging devices [9-11].

Besides graphene-like and, in general, nanocarbon materials, families of semiconducting inorganic systems, such as nanostructured transition metal dichalcogenides (TMDs, 
i.e., $\mathrm{MoS}_{2}, \mathrm{WS}_{2}$ ) and oxides (i.e., $\mathrm{TiO}_{2}$, perovskites) $[12,13]$, are attractive candidates for heterostructures and hybrid combinations.

Notice that each layer within two-dimensional layered materials (2DLMs) consists of a covalently bonded, dangling-bond-free lattice, which provides the in-plane stability of 2D crystals, whereas relatively weak, van-der-Waals-like interactions are able to keep the neighboring layers together [14,15]. This makes it feasible to isolate, mix, and match highly different atomic layers to create a wide range of van der Waals heterostructures (vdWHs) without the constraints of lattice matching and processing compatibility, in a sequence with one-atom-plane precision [15-17].

In this context, a large amount of $\mathrm{MoS}_{2} / \mathrm{TiO}_{2}$-based heterostructures with higher performance with respect to the individual $\mathrm{MoS}_{2}$ and $\mathrm{TiO}_{2}$-based materials have been obtained $[18,19]$. As a matter of fact, $\mathrm{MoS}_{2}$ has been considered of great interest to perform $\mathrm{MoS}_{2} / \mathrm{TiO}_{2}$ hybrid composites, due to its absorption in the UV-visible range, and then its ability to increase the visible light absorption of $\mathrm{TiO}_{2}$-based systems [20,21]. However, $\mathrm{TiO}_{2}$, despite being an excellent photocatalyst, is known to absorb only a small portion of the solar spectrum in the UV region (3\% of the sunlight spectrum) [22].

Therefore, in order to exploit new and advanced applications, the relationship between the structure and properties in $\mathrm{MoS}_{2} / \mathrm{TiO}_{2}$-based composites has to be investigated. Concerning this point, lattice mismatch - that is, different lattice constants and atomic arrangements between $\mathrm{MoS}_{2}$ and $\mathrm{TiO}_{2}$ - causes $\mathrm{TiO}_{2}$ particles to agglomerate, thus achieving poor interfacial contact of the $\mathrm{TiO}_{2}$ particles with the $\mathrm{MoS}_{2}$ layered material. As it is known that the interface plays a key role in charge carrier separation and migration [23], many efforts have been devoted to grow $2 \mathrm{D} \mathrm{MoS}$ nanosheets on the most exposed $\mathrm{TiO}_{2}$ facets as substrates, which provide a larger contact specific surface areas for charge carrier transfers [5]. In particular, 2D anatase $\mathrm{TiO}_{2}$ nanosheets with exposed \{001\} facets [24] have especially attracted great interest in the nucleation and growth of $\mathrm{MoS}_{2}$ nanosheets $[8,25]$.

Considering the favorable optical properties of $\mathrm{MoS}_{2}$ - that is, excitonic absorption bands in the visible spectra together with the occurring of efficient charge transfer phenomena between $\mathrm{MoS}_{2}$ nanoparticles and $\mathrm{TiO}_{2}$ nanosheets [26] - recently, highly dispersed $\mathrm{MoS}_{2}$ nanoparticles have been prepared through different methods, including ex situ and in situ approaches. It has been reported that, from ex situ synthesis at low cost and the scalable production of highly heterogeneous $\mathrm{MoS}_{2} / \mathrm{TiO}_{2}$-based composites, weak interface interactions are obtained $[5,19]$. On the contrary, composites with strong interface contacts can be achieved, although at a low yield, from in situ strategies [5]. It is known that from in situ methods, atomic scale assembling and then growth of well-defined $\mathrm{MoS}_{2}$ slabs can be obtained, thus providing effective chemical interactions at the interface. Concerning the in situ strategies, chemical solution methods are mainly used to prepare $\mathrm{MoS}_{2} / \mathrm{TiO}_{2}$-based composites, where $\mathrm{MoS}_{2}$ nanoplatelets grow on $\mathrm{TiO}_{2}$ basal planes [5]. As a result, 2D-2D $\mathrm{MoS}_{2} / \mathrm{TiO}_{2}$ nanosheets exhibit high activity due to the large contact area, although it was reported that heterostructures coming from solution chemical methods show a low amount of exposed active edge sites [5].

Notwithstanding the great interest in $\mathrm{MoS}_{2} / \mathrm{TiO}_{2}$ systems, there is a limited number of studies on $\mathrm{TiO}_{2}$ nanosheets with exposed $\{001\}$ facets decorated with $\mathrm{MoS}_{2}$ slabs obtained from either ex situ or in situ approaches. Among these studies, different structures including 2D nanojunctions [8,27], $\mathrm{MoS}_{2}$ nanoparticles or nanosheets decorating $\mathrm{TiO}_{2}$ nanosheets [25,28-30], and $\mathrm{MoS}_{2}$ quantum dots (QDs) at the surface of $\mathrm{TiO}_{2}$ sheets were found very effective for enhanced photocatalytic $\mathrm{H}_{2}$ production and dyes photodegradation. Furthermore, it is known that in $\mathrm{MoS}_{2} / \mathrm{TiO}_{2}$ hybrid nanosheets' interfacial charge transfer mechanisms [31], together with improved separation efficiency of photogenerated $\mathrm{e}^{-} \mathrm{h}^{+}$pairs caused by the presence of $\mathrm{MoS}_{2}$ as cocatalysts [25,30], have a role in increasing the photocatalytic activity.

According to some authors, $\mathrm{TiO}_{2}$ nanosheets are preliminarily prepared by using a fluorine-based morphology controlling agent, which gives rise to the formation of Ti-F bonds on the exposed $\mathrm{TiO}_{2}\{001\}$ facets [32-34]. The surface fluorine species, due to their 
instability during hydrothermal treatment, tend to be replaced by hydroxyl groups, which in turn absorb Mo precursors, such as $\mathrm{MoO}_{4}{ }^{2-}$ and $\mathrm{MoS}_{4}{ }^{2-}$ anions, which are then reduced in situ by the $\mathrm{S}$ source to form $2 \mathrm{D}-2 \mathrm{D} \mathrm{MoS}_{2} / \mathrm{TiO}_{2}$ nanosheets $[5,8,35]$.

Based on these published results and on the lack of comparison between such layered systems prepared by in situ and ex situ approaches, in the present work, 2D-2D MoS $2 / \mathrm{TiO}_{2}$ hierarchical nanostructures have been obtained either via an ex situ approach, which implies a preliminary exfoliation/fragmentation under solvent assisted ultrasonication of bulk $\mathrm{MoS}_{2}$, followed by subsequent wet impregnation of $\mathrm{TiO}_{2}$ nanosheets and via an in situ approach, from a molybdenum oxide precursor in a sulfiding atmosphere $\left(\mathrm{H}_{2} \mathrm{~S}\right)$, which gives rise to the formation of highly dispersed and strongly anchored $\mathrm{MoS}_{2}$ slabs on $\mathrm{TiO}_{2}$ nanosheets.

In this paper, the morphology, structure, vibrational, and optical properties of the samples obtained from the ex situ and in situ strategies are compared. Particular attention was paid to the different stacking degrees, the size distribution and dispersion of the $\mathrm{MoS}_{2}$ nanosheets, decorating the $\mathrm{TiO}_{2}$ supports, together with investigation of the surface sites on the main exposed faces, by means of adsorption of a suitable probe molecule. In this regard, we have used for the first time $\mathrm{CO}$ molecules for probing the surface of $\mathrm{MoS}_{2} / \mathrm{TiO}_{2}$ combined heterostructures.

As a matter of fact, it is known from FTIR spectra that $\mathrm{CO}$ adsorption at low temperature is a highly sensitive probe to detect small differences in the Lewis acidity of the exposed sites (e.g., $\mathrm{Ti}^{4+}$ centers). The greater the electrophilic character of the metal cation is, the higher the upshift of the signal is with respect to the value of $v C O$ in the gas phase $\left(2143 \mathrm{~cm}^{-1}\right)$ [36]. In conclusion, it will be shown that on samples obtained by in situ strategy, self-aggregation phenomena are hindered by the $\mathrm{MoS}_{2}$ / surface interaction, that is by the formation of highly dispersed and strongly anchored $\mathrm{MoS}_{2}$ nanosheets, which in turn is favored by sulfur doping.

\section{Materials and Methods}

\subsection{Materials}

\subsubsection{Synthesis of the $\mathrm{TiO}_{2}$ Nanosheets}

$\mathrm{TiO}_{2}$ nanosheets have been obtained via a solvothermal procedure, which we briefly summarize because many papers have already reported on this subject [35,37]. In particular, $25 \mathrm{~mL}$ of Ti(OBu$)_{4}$ (Titanium (IV) butoxide) was poured in a $150 \mathrm{~mL}$ Teflon-lined stainless steel reactor and $3.5 \mathrm{~mL}$ of concentrated hydrofluoric acid was added dropwise under stirring, at $523 \mathrm{~K}$ for $24 \mathrm{~h}$. The resulting bluish paste was centrifuged and washed with acetone to remove the residual organics and then with water. Finally, the obtained aqueous suspension was freeze-dried obtaining bluish powder $\mathrm{TiO}_{2}$ nanosheets (hereafter $\mathrm{TiO}_{2}$ $\mathrm{n}$-sh). In order to remove the fluorides from the surface, $\mathrm{TiO}_{2} \mathrm{n}$-sh were washed with $0.1 \mathrm{M}$ $\mathrm{NaOH}$, then centrifuged (5000 rpm, 15 min), keeping the supernatant for quantification of fluorides and Ti species by ion chromatography and inductively coupled plasma mass spectrometry (ICP-MS), respectively. The paste of $\mathrm{TiO}_{2}$ nanoparticles was again centrifuged in $0.1 \mathrm{M} \mathrm{HNO}_{3}(40 \mathrm{~mL}, 5000 \mathrm{rpm}, 15 \mathrm{~min})$ and ultrapure water to remove the surface $\mathrm{Na}^{+}$ ions. Notice that the $\mathrm{TiO}_{2}$ nanosheets were analyzed by Auger electron spectroscopy, XPS, and TOF-SIMS analyses in previous works (see the specific literature) $[35,38,39]$. Calcination in air at $873 \mathrm{~K}$, for $60 \mathrm{~min}$, and then cooling down to $298 \mathrm{~K}$ in the closed furnace for approximately $10 \mathrm{~h}$ were performed to remove bulk and the surface fluorides.

\subsubsection{Synthesis of the $\mathrm{MoS}_{2} / \mathrm{TiO}_{2}$ Nanosheets by Ex Situ Method}

A dispersion of $2 \mathrm{mg}$ of $\mathrm{MoS}_{2}$ in $10 \mathrm{~mL}$ of water/ethanol mixture $(5.5 \mathrm{~mL}$ water and $4.5 \mathrm{~mL}$ ethanol) was sonicated preliminarily in an ultrasonic bath for $5 \mathrm{~min}$, then subjected to further sonication at $20 \mathrm{kHz}$ for $6 \mathrm{~h}$ by means of a VCX 500 Sonics Vibracell ultrasonic processor (power $500 \mathrm{~W}$ ), equipped with a Ti alloy tapered microtip ( $\mathrm{d}=3 \mathrm{~mm}$, $30 \%$ amplitude). A great intensity of cavitation can be obtained by the small diameter horn in the restricted volume of the solution, which has been placed in an ice bath to control the 
temperature during the whole sonication step. The obtained dark gray and turbid solution was then centrifuged (for $30 \mathrm{~min}$ at $4000 \mathrm{rpm}$ ), thus allowing the sedimentation of bigger particles and the separation of a clear light green-yellow supernatant solution to occur [40]. The supernatant portion of the dispersed solution (about $9 \mathrm{~mL}$ ) is then transferred to a suitable test tube, in order to study its optical properties. Subsequently, the $\mathrm{TiO}_{2}$ nanosheets powder $(0.13 \mathrm{~g})$ was placed on a glass disk and then on a temperature-controlled heating plate $(363 \mathrm{~K})$, where it was impregnated with $9 \mathrm{~mL}$ of the sonicated $\mathrm{MoS}_{2}$ solution. This temperature allows for easy evaporation of the $\mathrm{H}_{2} \mathrm{O} / \mathrm{EtOH}$ solvent. Then, the obtained sample was placed in an oven at $373 \mathrm{~K}$ overnight. The main steps are summarized in Scheme 1, left side.

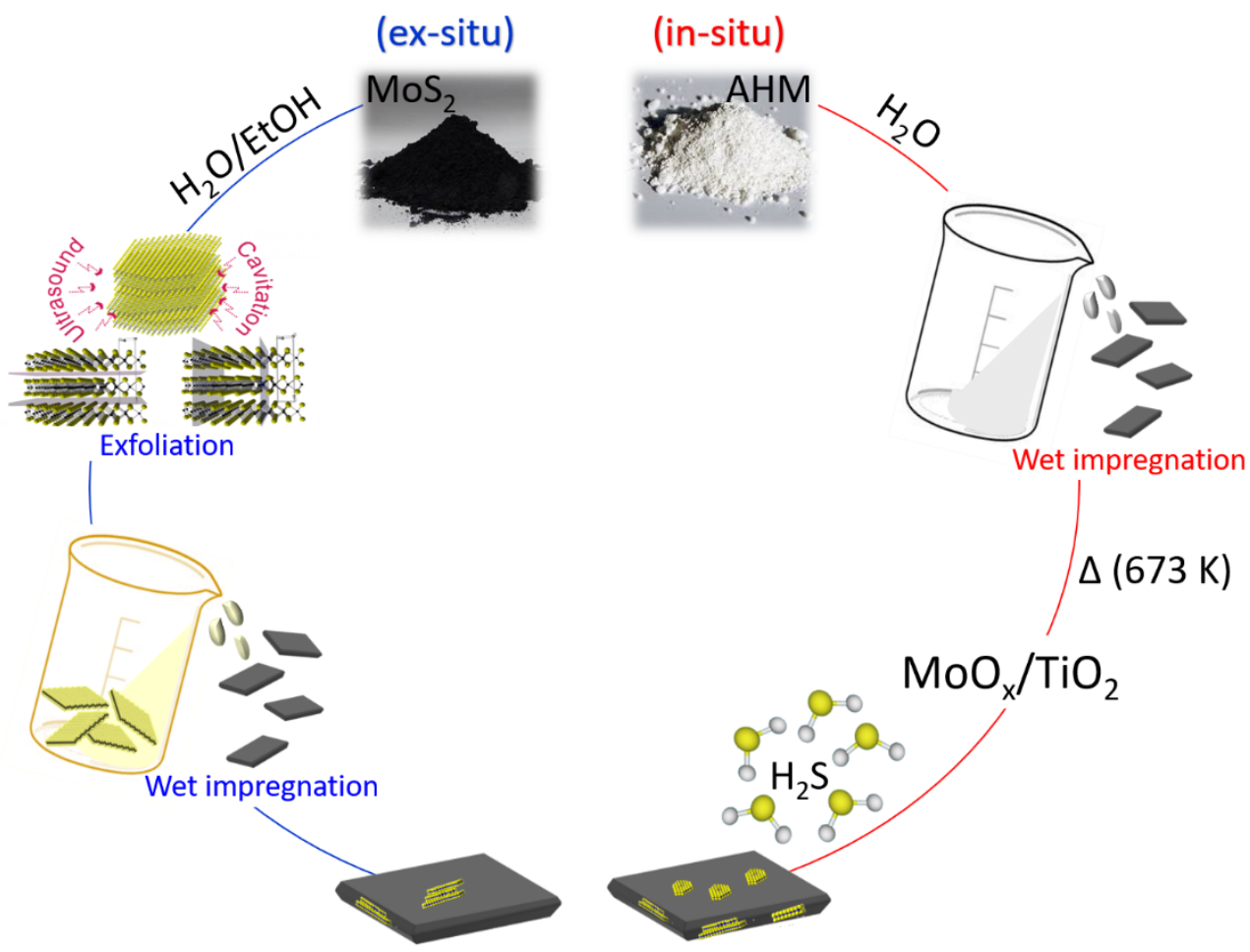

Scheme 1. Main steps of the synthesis processes of the $\mathrm{MoS}_{2} / \mathrm{TiO}_{2}$ nanosheets obtained by an ex situ method (on the left side) and by an in situ method (on the right side).

\subsubsection{Synthesis of the $\mathrm{MoS}_{2} / \mathrm{TiO}_{2}$ Nanosheets by In Situ Method}

A clear solution of $0.066 \mathrm{~g}$ of ammonium heptamolybdate $\left(\mathrm{AHM},\left(\mathrm{NH}_{4}\right)_{6} \mathrm{Mo}_{7} \mathrm{O}_{24} \times 4 \mathrm{H}_{2} \mathrm{O}\right)$ in $2 \mathrm{~mL}$ of distilled water under stirring was prepared first. Then, the solution was dripped onto the $\mathrm{TiO}_{2}$ nanosheets powder $(2 \mathrm{~g})$ and mixed with a glass rod. The mixture was placed in an oven at $323 \mathrm{~K}$ overnight. With this procedure, hybrids with Mo $3 \%$ by weight are obtained. Titania nanosheet powder was pressed in self-supporting pellets by means of a hydraulic press and inserted in a gold frame (suitable for FTIR measurements in situ). Later, it was placed in a muffle where the decomposition of AHM into molybdenum oxide occurred. In particular, the decomposition of $\mathrm{AHM}$ in $\mathrm{MoO}_{\mathrm{x}}$ and the removal of ammonia and water have been obtained by heat treatment in air at $673 \mathrm{~K}$ for $12 \mathrm{~h}$, having set a temperature ramp of $5 \mathrm{~K}$ per minute. The $\mathrm{MoO}_{\mathrm{x}}$ sample was activated under dynamic vacuum at $673 \mathrm{~K}$ for $30 \mathrm{~min}$, and then twice oxidized in oxygen atmosphere (40 Torr) at the same temperature and time. The oxidized sample was sulfided at $673 \mathrm{~K}$, in the $\mathrm{H}_{2} \mathrm{~S}$ atmosphere (30 Torr) for $1 \mathrm{~h}$, then outgassed. The sulfidation process was carried out twice. The main steps are summarized in Scheme 1, right side.

\subsection{Methods}

The structure and morphology of the samples have been investigated according to the following: 
(i) X-ray diffraction (XRD) patterns of samples have been collected with a PAN analytical PW3050/60 X'Pert PRO MPD diffractometer with a Cu anode and a Ni filter, in BraggBrentano configuration. The diffractograms were acquired in an interval equal to $10^{\circ} \leq 2 \theta \leq 80^{\circ}$ with an acquisition step of $0.02^{\circ}$.

(ii) High-resolution transmission electron microscopy (HRTEM) images have been obtained with a JEOL 3010-UHR HRTEM microscope operating at $300 \mathrm{kV}$ with a point-topoint resolution of $0.12 \mathrm{~nm}$, equipped with a $2 \mathrm{k} \times 2 \mathrm{k}$ pixels Gatan US1000 CCD camera.

(iii) Raman spectra were acquired in backscattering mode using a Renishaw In Via Raman spectrophotometer, equipped with an $\mathrm{Ar}^{+}$laser emitting at $514.5 \mathrm{~nm}$. The backscattered light was analyzed by a grid with 1200 lines $/ \mathrm{mm}$ and detected by a CCD detector. The effects of the radiation damage on the samples were reduced by limiting the output power to $0.5 \%$.

(iv) FTIR spectra were acquired by means of a Bruker IFS 66 FTIR spectrometer equipped with a cryogenic MCT detector with $2 \mathrm{~cm}^{-1}$ resolution. Each titania sample was pressed in the form of a self-supporting pellet with "optical thickness" of ca. $10 \mathrm{mg} \cdot \mathrm{cm}^{-2}$. To investigate the surface properties, the $\mathrm{CO}$ probe molecule was dosed on samples by means of a gas manifold connected to the IR cell, thus allowing us to perform thermal treatments under vacuum and gas dosage. The spectra were collected after CO dosage (70 Torr) at $77 \mathrm{~K}$ in an IR cell designed for liquid $\mathrm{N}_{2}$ flow conditions.

(v) The optical properties of the samples dispersed in solution have been investigated by means of transmittance mode using quartz cuvettes with an optical path of $1 \mathrm{~cm}$, while the properties of the powder samples have been studied by means of diffuse reflectance (DR) mode. A Varian Cary UV 5000 spectrophotometer, equipped with a diffuse reflectance sphere, was used in the 2500-190 nm wavelength range.

\section{Results and Discussion}

\subsection{Structure and Morphology by Means of XRD, HRTEM, and Raman Analyses}

\subsubsection{XRD Analysis}

The X-ray diffraction patterns of $\mathrm{MoS}_{2} / \mathrm{TiO}_{2} \mathrm{n}$-sh obtained by in situ and ex situ methods are compared together with the XRD patterns of $\mathrm{MoS}_{2}$ bulk (Fluka) and of the native $\mathrm{TiO}_{2} \mathrm{n}$-sh powder (Figure 1). XRD diffraction patterns show peaks at $2 \theta=25.2^{\circ}$, $37.0^{\circ}, 37.8^{\circ}, 38.6^{\circ}, 48.0^{\circ}, 53.9^{\circ}$, and $55.1^{\circ}$, corresponding to (101), (103), (004), (112), (200), (105), and (211) diffraction planes of anatase (PDF card \#21-1272), and also match well with the native $\mathrm{TiO}_{2} \mathrm{n}$-sh XRD peaks (black pattern). Together with the aforementioned XRD features, the XRD pattern after wet impregnation with the $\mathrm{MoS}_{2}$ diluted dispersion in $\mathrm{H}_{2} \mathrm{O} / \mathrm{EtOH}$ exhibits three additional weak peaks at $2 \theta \cong 14.4^{\circ}, 32.7^{\circ}$, and at $39.5^{\circ}$, which correspond to the (002), (100), and (103) diffraction planes of hexagonal $\mathrm{MoS}_{2}$ (gray pattern). XRD diffraction fingerprints of $\mathrm{MoS}_{2}$ are not found for the in situ methods (red pattern) [41,42]. Surprisingly, although this sample has a Mo content of $3 \% \mathrm{wt} / \mathrm{wt}$, no XRD fingerprints of $\mathrm{MoS}_{2}$ are present after reaction with $\mathrm{H}_{2} \mathrm{~S}$. At this stage, we can only assume that the sulfurization products of the Mo-based species present on $\mathrm{TiO}_{2} \mathrm{n}$-sh are remarkably amorphous and/or very small in size (smaller than a few $\mathrm{nm}$ ). 


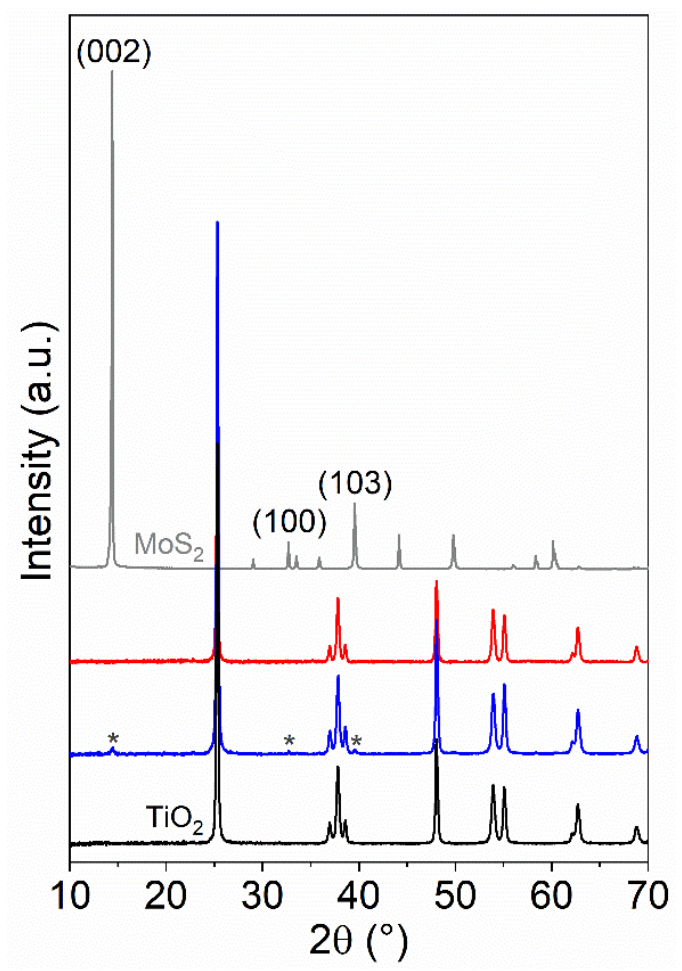

Figure 1. XRD patterns of $\mathrm{TiO}_{2}$ anatase nanosheet (n-sh) pre-treated at $873 \mathrm{~K}$ (black line), of $\mathrm{MoS}_{2} / \mathrm{TiO}_{2} \mathrm{n}$-sh prepared by the ex situ method (blue line), of $\mathrm{MoS}_{2} / \mathrm{TiO}_{2} \mathrm{n}$-sh obtained by the in situ approach (red line), and of pure bulk $\mathrm{MoS}_{2}$ used as a reference material (grey line). Asterisks $\left({ }^{*}\right)$ show the weak diffraction features typical of $\mathrm{MoS}_{2}$.

\subsubsection{HRTEM Images}

The $\mathrm{MoS}_{2} / \mathrm{TiO}_{2} \mathrm{n}$-sh (36 $\mathrm{mL} \mathrm{MoS}_{2}$ ) sample obtained by the ex situ method was TEM and HRTEM imaged, as shown in Figure $2 \mathrm{a}-\mathrm{d}$. $\mathrm{TiO}_{2}$ nanosheets with lateral dimensions in the 50-200 nm range (Figure 2a) and thicknesses of about 30-40 nm (Figure 2b) are observed from the lower resolution TEM images. In the HRTEM image in Figure 2c, where nanoparticles are perpendicularly oriented to the electron beam, the $\mathrm{TiO}_{2}$ nanosheets are highly crystalline and expose well-defined interference fringes, $3.53 \AA$ spaced due to anatase (101) planes [43]. Cavities with rectangular shape, resulting from the nanosheet preparation, can be observed by the variation in intensity across different regions in the nanoparticles. A small nanoparticle with lateral dimension of $20 \mathrm{~nm}$ and $5 \mathrm{~nm}$ in thickness, exposes $6.5 \AA$ spaced interference fringes that are disrupted in the center (Figure 2d). Such a nanoparticle of irregular shape can be safety assigned to a $\mathrm{MoS}_{2}$ slab with the stacking number $>5-6$ [44].

The $\mathrm{MoS}_{2} / \mathrm{TiO}_{2} \mathrm{n}$-sh (Mo 3 wt.\%) sample obtained by the in situ method is TEM and HRTEM imaged at different magnifications in Figure $3 \mathrm{a}-\mathrm{d} . \mathrm{TiO}_{2}$ nanosheets have a prevalent orientation perpendicular to the electron beam (Figure 3a), thus exposing their basal sizes in the 30-100 $\mathrm{nm}$ range, although a few nanosheets expose their thicknesses of about $20-30 \mathrm{~nm}$ as obtained from remarkable image contrast (Figure $3 \mathrm{~b}$ ). The selected regions in Figure 3a,b are HRTEM imaged in Figure $3 c, d$, where regular interference fringes, $3.53 \AA$ spaced, that correspond to (101) planes of anatase are decorated with more irregular fringes. Such fringes have spacings of about 6.5-6.7 $\AA$ and can be assigned to thin $\mathrm{MoS}_{2}$ slabs at the surface of anatase nanoparticles [41,42]. Furthermore, a stacking number of $3 \pm 2$ layers and basal sizes of $2-10 \mathrm{~nm}$ can be observed. It is worthy of attention that the $\mathrm{MoS}_{2}$ slabs as obtained by the in situ preparation appear to be thinner and more defective (i.e., basal plane interruptions, more curved structures decorating the anatase facets) with respect to the slabs obtained by the ex situ preparation, despite the higher $\mathrm{MoS}_{2}$ concentration. 


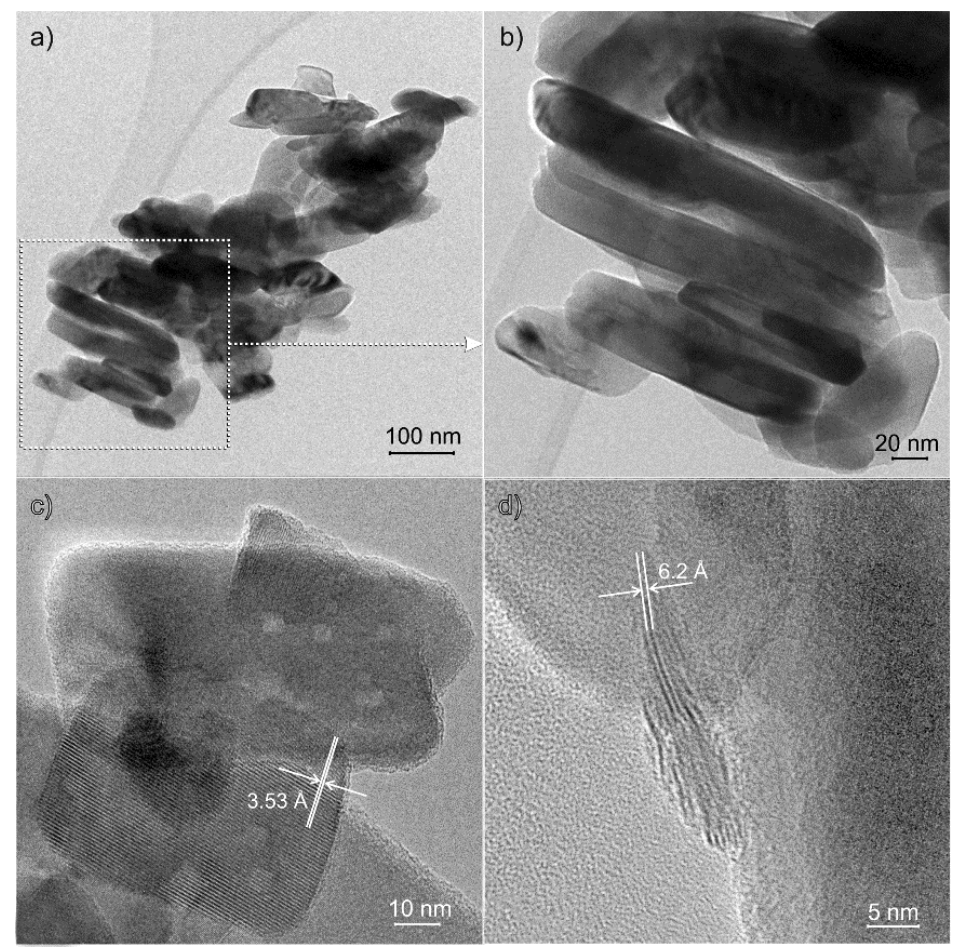

Figure 2. TEM and HRTEM images obtained at different magnifications of $\mathrm{MoS}_{2} / \mathrm{TiO}_{2} \mathrm{n}$-sh prepared by the ex situ method: (a) TEM image of $\mathrm{TiO}_{2}$ nanosheets aggregates; (b) enlarged view of the selected region in panel (a); (c) HRTEM image of $\mathrm{TiO}_{2}$ nanosheets exposing well-defined interference fringes; (d) HRTEM image of $\mathrm{MoS}_{2}$ slab with the stacking number >5-6.

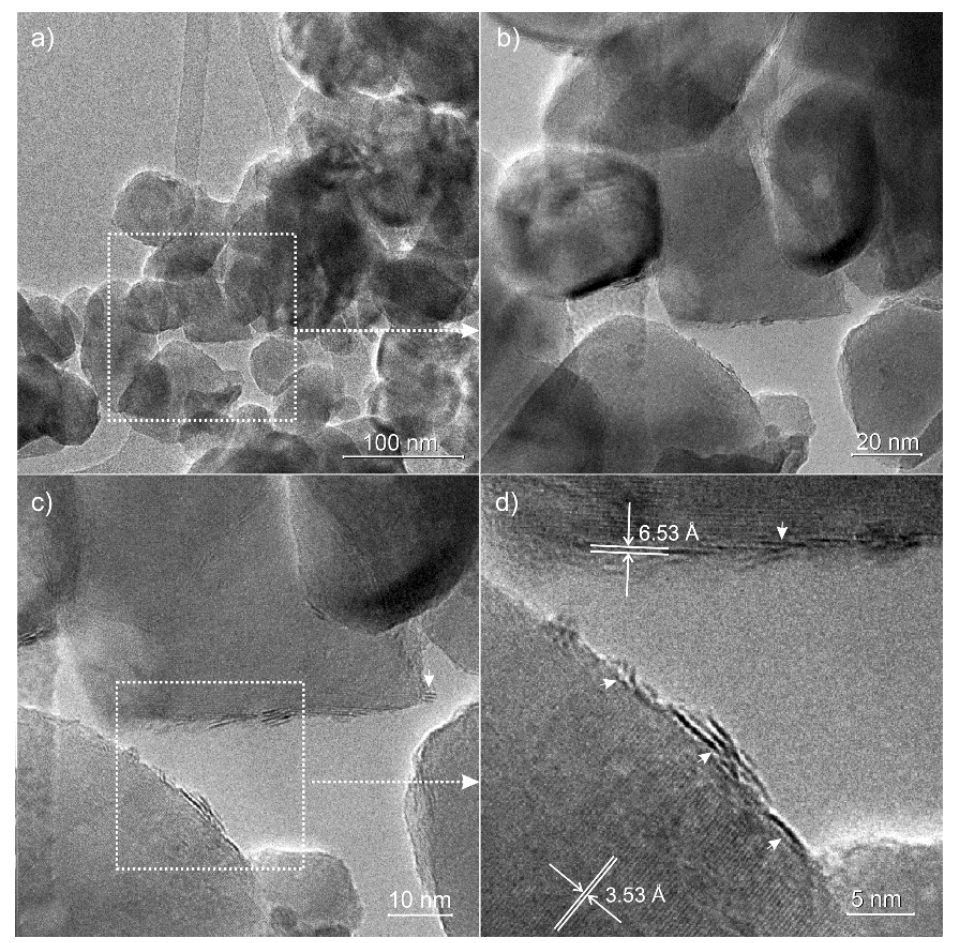

Figure 3. TEM and HRTEM images obtained at different magnifications of $\mathrm{MoS}_{2} / \mathrm{TiO}_{2} \mathrm{n}$-sh prepared by in situ method: (a) TEM image of $\mathrm{MoS}_{2} / \mathrm{TiO}_{2}$ n-sh aggregates; (b) enlarged view of the selected region in panel (a); (c,d) HRTEM images at two different levels of magnification of the selected region in panel (b), where regular interference fringes, $3.53 \AA$ spaced, that correspond to (101) planes of anatase are decorated with more irregular fringes due to $\mathrm{MoS}_{2}$ nanoparticles. 


\subsubsection{Raman Investigation}

In Figure 4a, the Raman spectra, recorded with the $514 \mathrm{~nm}$ laser line, of $\mathrm{MoS}_{2} / \mathrm{TiO}_{2}$ n-sh obtained by ex situ (blue line) and in situ methods (red line) and of $\mathrm{TiO}_{2}$ anatase nanosheet (n-sh) pretreated at $873 \mathrm{~K}$ (black line) are compared with that of bare $\mathrm{MoS}_{2}$, used as a reference material (grey line). Considering the Raman spectrum of pure $\mathrm{TiO}_{2}$ nanosheets (black line), the typical anatase $\mathrm{TiO}_{2}$ fingerprint can be recognized. As a matter of fact, the four bands at $144,396,514$, and $636 \mathrm{~cm}^{-1}$ are ascribed to the $\mathrm{E}_{\mathrm{g}}, \mathrm{B}_{1 \mathrm{~g}}$, $\mathrm{A}_{1 \mathrm{~g}}$, and $\mathrm{E}_{\mathrm{g}}$ Raman active modes, respectively, of the anatase phase, as described in the literature $[45,46]$.

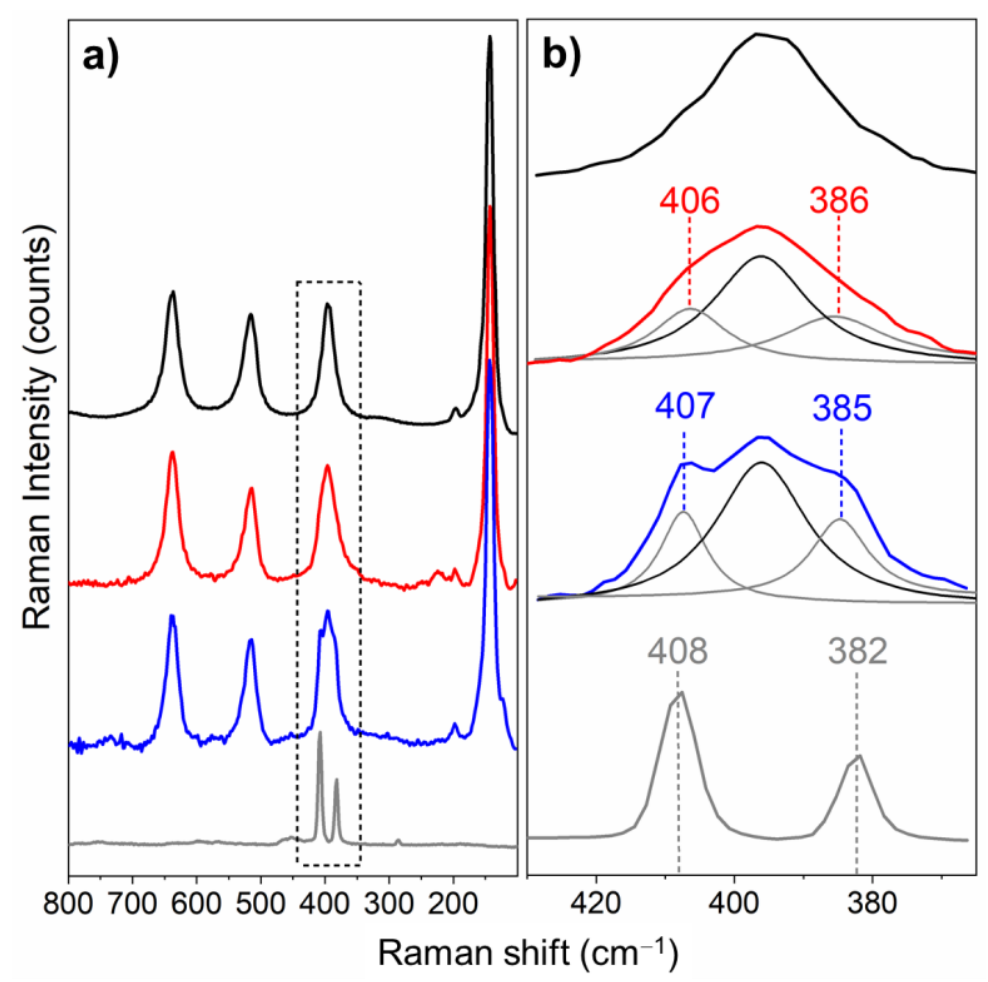

Figure 4. (a) Raman spectra, in the $800-100 \mathrm{~cm}^{-1}$ range, of pure bulk $\mathrm{MoS}_{2}$ used as a reference material (grey line), of $\mathrm{MoS}_{2} / \mathrm{TiO}_{2} \mathrm{n}$-sh obtained by the ex situ method (blue line), of $\mathrm{MoS}_{2} / \mathrm{TiO}_{2}$ n-sh obtained by the in situ method (red line), and of the $\mathrm{TiO}_{2}$ anatase nanosheet (n-sh) pretreated at $873 \mathrm{~K}$ (black line). All spectra were recorded with the $514 \mathrm{~nm}$ laser line. (b) Enlarged views in the $425-365 \mathrm{~cm}^{-1}$ range: the grey dashed lines in bulk $\mathrm{MoS}_{2}$ spectrum indicate the positions of the $\mathrm{E}^{1}{ }_{2 \mathrm{~g}}$ and $\mathrm{A}_{1 \mathrm{~g}}$ peaks, respectively. Deconvolution of the Raman patterns are shown for ex situ (blue line) and in situ (red line) samples.

Moving to both the $\mathrm{MoS}_{2} / \mathrm{TiO}_{2} \mathrm{n}$-sh obtained by the ex situ method (blue line), and by the in situ method (red line), it can be observed that the feature centered at $396 \mathrm{~cm}^{-1}$, assigned to the $\mathrm{TiO}_{2}$ anatase phase, is split into two components at 407 and $385 \mathrm{~cm}^{-1}$ (blue line), and at 406 and $386 \mathrm{~cm}^{-1}$, (red line), which can be ascribed to $\mathrm{MoS}_{2} \mathrm{~A}_{1 \mathrm{~g}}$ and $\mathrm{E}^{1}{ }_{2 \mathrm{~g}}$ first-order Raman active modes, respectively (Figure $4 \mathrm{~b}$ ) [20]. The $\mathrm{A}_{1 \mathrm{~g}}$ mode is explained with a vibration along the stacking of $\mathrm{MoS}_{2}$, while the $\mathrm{E}^{1}{ }_{2 \mathrm{~g}}$ mode is related to the lateral extension of the $\mathrm{MoS}_{2}$ sheets. The asymmetry of both signals suggests the contribution of a variety of sites located on the $\mathrm{MoS}_{2}$ boundaries characterized by slightly different nuclearity, together with the formation of small sulfide particles.

Notice that on $\mathrm{MoS}_{2} / \mathrm{TiO}_{2} \mathrm{n}$-sh obtained by the in situ method (Figure 4a, red line), a peak at about $227 \mathrm{~cm}^{-1}$ has been observed, which has been assigned to LA phonons at the $\mathrm{M}$ point [47]. According to the authors, a relationship between the intensity ratio of the LA(M) peak and each of the first-order peaks has been found, which suggests a practical 
route to quantify defects in single-layer $\mathrm{MoS}_{2}$ using Raman spectroscopy, thus highlighting an analogy between the LA(M) peak in $\mathrm{MoS}_{2}$ and the D peak in graphene.

From Figure $4 b$, a difference of the frequency values between the $A_{1 g}$ and $E_{2 g}^{1}$ modes of $\cong 20 \mathrm{~cm}^{-1}$ for $\mathrm{MoS}_{2} / \mathrm{TiO}_{2} \mathrm{n}$-sh obtained by in situ (red line), $\cong 22 \mathrm{~cm}^{-1}$ for $\mathrm{MoS}_{2} / \mathrm{TiO}_{2}$ n-sh obtained by ex situ (blue line), and $\cong 26 \mathrm{~cm}^{-1}$ for the reference bare $\mathrm{MoS}_{2}$ can be calculated. Reported in the literature as well, the difference of the frequency values between $\mathrm{A}_{1 \mathrm{~g}}$ and $\mathrm{E}_{2 \mathrm{~g}}^{1}$ modes is indicative of the slab thickness [48]. This means that a relationship between the position of the $\mathrm{A}_{1 \mathrm{~g}}$ and $\mathrm{E}^{1}{ }_{2 \mathrm{~g}}$ vibrational modes and the number of layers in the $\mathrm{MoS}_{2}$ particles has been established [41,49].

Moreover, most of these studies focused on materials obtained by the ex situ method, via exfoliation and deposition on flat supports of bulk $\mathrm{MoS}_{2}$. Therefore, a relationship has not been systematically investigated for $\mathrm{MoS}_{2}$ particles grown on oxide particles as a support (in situ method). As a matter of fact, in the case of highly dispersed supported $\mathrm{MoS}_{2}$, the morphology (i.e., effect of particle roughness and curvature) and surface properties of the support (i.e., preferential growth of peculiar crystal faces and surface defects) may affect the shape and positions of the $\mathrm{MoS}_{2}$ Raman bands, thus meaning that the $\mathrm{A}_{1 \mathrm{~g}}$ and $\mathrm{E}^{1}{ }_{2 \mathrm{~g}}$ peak positions cannot be taken as a direct reference of $\mathrm{MoS}_{2}$ staking level. However, by reasonably applying the established relationships [50] to our $\mathrm{MoS}_{2} / \mathrm{TiO}_{2}$ nanosheets, an average stacking order of $2 \pm 1$ layers per particle could be estimated for samples coming from the in situ method, whereas a higher stacking number of 3-4 for samples obtained by the ex situ method can be found, in agreement with XRD and HRTEM analyses.

\subsection{Optical Properties by UV-vis Spectroscopy}

Due to the close relation between the optical properties of $\mathrm{MoS}_{2} / \mathrm{TiO}_{2}$ nanosheets and their morphology/structure, UV-Vis-NIR spectra can give detailed information on the nature and properties of both the sulfided phase and the support, as well as on their electronic structure. In Figure 5, the UV-vis spectra of $\mathrm{TiO}_{2}$ anatase nanosheets, $\mathrm{MoS}_{2} / \mathrm{TiO}_{2}$ obtained by the in situ approach, and $\mathrm{MoS}_{2} / \mathrm{TiO}_{2}$ obtained by the ex situ approach are compared to those of the $\mathrm{MoS}_{2}$ bulk, used as a reference. All the spectra were recorded in the diffuse reflectance mode and converted to equivalent absorption Kubelka-Munk units. The curve of the $\mathrm{TiO}_{2}$ nanosheets (black line) shows the typical absorption edge of $\mathrm{TiO}_{2}$-based systems, due to the transition from $\mathrm{O}^{2-}$ antibonding orbital to the $\mathrm{Ti}^{4+}$ lowest energy orbital [19]. On the basis of the literature data [51] and other previous results [40], it appears that the spectral features of the $\mathrm{MoS}_{2}$ reference (grey line) can be assigned as follows: (i) a first absorption threshold at about $700 \mathrm{~nm}$ associated to a direct transition at the K point [52,53]; (ii) two sharp peaks at $680 \mathrm{~nm}$ and at $622 \mathrm{~nm}$, on the high energy side of the $700 \mathrm{~nm}$ threshold, assigned to A and B excitonic transitions, respectively, whose separation energy can be explained with spin-orbit splitting at the top of the valence band at the $\mathrm{K}$ point [54]; (iii) a second threshold at about $500 \mathrm{~nm}$, due to a direct transition from the deep in the valence band to the conduction band; (iv) another two excitonic transitions at $482 \mathrm{~nm}(\mathrm{C})$, and at $399 \mathrm{~nm}(\mathrm{D})$, also associated with the $500 \mathrm{~nm}$ threshold transition [51]; and (v) a third threshold at about $350 \mathrm{~nm}$ due to transitions from deep in the valence band [52]. The curve of the $\mathrm{MoS}_{2} / \mathrm{TiO}_{2}$ hybrid system obtained by the in situ approach (red line) shows a continuum and wide absorption over the UV-visible range, due to the presence above the valence band, of new electronic states arising from sulfur-oxygen exchange reactions at the surface of $\mathrm{TiO}_{2}$ nanosheets. These states result from the mixing of Sulphur 3p atomic orbitals with the $\mathrm{TiO}_{2}$ valence band [19]. Notice that reduced molybdenum species on $\mathrm{TiO}_{2}$ defective nanosheets have to be considered, although hidden inside the wide and intense absorption. This could be further proof of the formation of thin $\mathrm{MoS}_{2}$ platelets [40,48]. The typical $\mathrm{MoS}_{2}$ excitonic bands A and B are shifted to higher energies as compared to those of $\mathrm{MoS}_{2}$ bulk, meaning a quantum confinement of the excitons, due to the low dimension of the $\mathrm{MoS}_{2}$ particles, which is in agreement with the HRTEM and XRD results. The features in the $400-500 \mathrm{~nm}$ range, already 
explained with the $\mathrm{C}$ and $\mathrm{D}$ excitons of $\mathrm{MoS}_{2}$, overlap inside a broad band, as expected for a highly dispersed supported material.

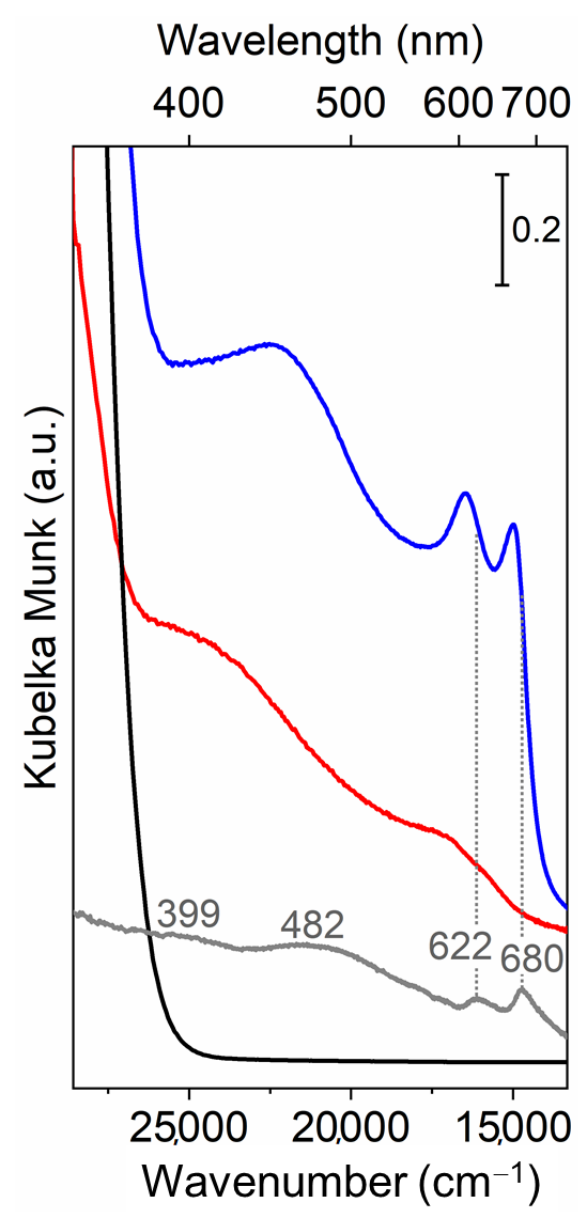

Figure 5. UV-vis spectra of $\mathrm{TiO}_{2}$ anatase nanosheet (n-sh) pretreated at $873 \mathrm{~K}$ (black line), of pure bulk $\mathrm{MoS}_{2}$ used as a reference material (grey line), of in situ $\mathrm{MoS}_{2} / \mathrm{TiO}_{2} \mathrm{n}$-sh (red line), and of ex situ $\mathrm{MoS}_{2} / \mathrm{TiO}_{2} \mathrm{n}$-sh (blue line). The grey dotted lines indicate the positions of the typical $\mathrm{MoS}_{2} \mathrm{~A}$ and $\mathrm{B}$ excitonic transitions. All spectra were recorded in the diffuse reflectance mode and converted to equivalent absorption Kubelka-Munk units. The reflectance responses are reported vs. wavenumber (bottom axis) and vs. wavelength (top axis).

Similar features are present in the $\mathrm{MoS}_{2} / \mathrm{TiO}_{2}$ hybrid obtained through the ex situ approach (blue line), although slightly downward shifted, as compared to the in situ sample. Considering both the systems in mor detail, obtained by in situ and ex situ approaches (red and blue lines, respectively), if compared to those of the reference $\mathrm{MoS}_{2}$ bulk, it can be observed that the energy values of A and B excitons are only slightly upward shifted, whereas relevant shifts are observed for the $C$ and $D$ excitons envelope, because quantum size effects more significantly affect the $C$ and $D$ bands [52].

Notice that quantum size effects have been related to the low dimensionality of the $\mathrm{MoS}_{2}$ particles along the c direction, which is due to a low number of layers, but the small dimension of the $\mathrm{MoS}_{2}$ platelets along the "in-plane" a and b directions can also play a role [54]. According to this, we can conclude that the sample synthesized via the in situ approach has smaller $\mathrm{MoS}_{2}$ particles than the sample synthesized via the ex situ method, with some level of particle stacking observed in the last case (as HRTEM imaged in Figures 2 and 3). 


\subsection{Surface Vibrational Properties by FTIR}

FTIR spectra of $\mathrm{CO}$ adsorbed at liquid nitrogen temperature, at decreasing coverages up to the residual pressure of $4 \times 10^{-4}$ Torr, on the surface of $\mathrm{TiO}_{2} \mathrm{n}$-sh (pretreated at $873 \mathrm{~K})$, of $\mathrm{MoS}_{2} / \mathrm{TiO}_{2} \mathrm{n}$-sh $(36 \mathrm{~mL} \mathrm{MoS} 2)$ (pretreated at $\left.673 \mathrm{~K}\right)$, and of $\mathrm{MoS}_{2} / \mathrm{TiO}_{2} \mathrm{n}$-sh (Mo 3\% wt/wt) (pretreated at $673 \mathrm{~K}$ ) are shown in Figure 6. The main feature at $2159 \mathrm{~cm}^{-1}$ on the $\mathrm{TiO}_{2} \mathrm{n}$-sh sample (Figure $6 \mathrm{a}$ ) is due to $\mathrm{CO}$ molecules adsorbed on the $\mathrm{Ti}^{4+}$ sites located on $(1 \times 4)$ reconstructed $(001)$ surfaces, together with a minor feature observed at $2179 \mathrm{~cm}^{-1}$, which has been assigned to CO molecules adsorbed on (101) surfaces, less extensive than (001), according to the data and models reported in the literature [35]. Moreover, a weak shoulder at ca. $2155 \mathrm{~cm}^{-1}$, which is hidden within the envelope of the band on the low frequency side, due to $\mathrm{CO}$ species interacting with the residual surface $\mathrm{OH}$ groups, can be detected. Notice that the band at $2159 \mathrm{~cm}^{-1}$ is fully reversible upon CO outgassing, whereas the peak at $\sim 2179 \mathrm{~cm}^{-1}$ remains almost unaffected at the temperature of the experiment. Furthermore, the maximum of the $2159 \mathrm{~cm}^{-1}$ band undergoes a quite negligible upward frequency shift upon decreasing $\mathrm{CO}$ pressure, approaching the singleton $v(\mathrm{CO})$, plausibly due to the fading away of weak lateral interactions (dynamic and static in type) within the $\mathrm{CO}$ adlayer. The low upshift of the singleton mode with respect to the CO stretching mode in the gas phase $\left(2143 \mathrm{~cm}^{-1}\right)$ together with the complete reversibility upon $\mathrm{CO}$ outgassing are explained with the low electrophilicity/reduced acidity of the $\mathrm{Ti}^{4+}$ sites on (001) surfaces, due to a screened electrostatic potential at these Ti sites, which are strongly bound to two oxygens. This agrees with the weakness of their interaction with CO [19].

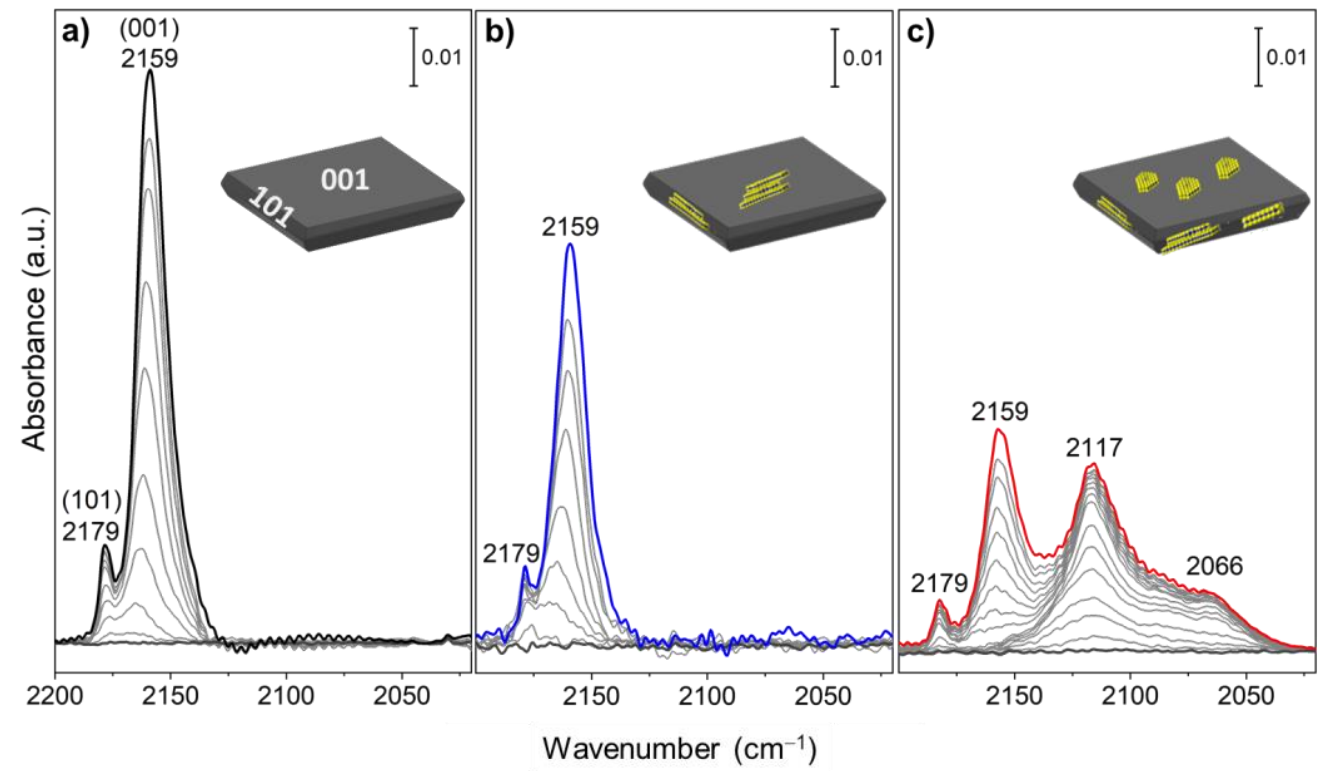

Figure 6. FTIR spectra of $\mathrm{CO}$ (30 Torr) adsorbed at $77 \mathrm{~K}$ at decreasing coverage on the surface of: (a) $\mathrm{TiO}_{2}$ anatase nanosheet (n-sh) pretreated at $873 \mathrm{~K},\left(\right.$ b) $\mathrm{MoS}_{2} / \mathrm{TiO}_{2} \mathrm{n}$-sh obtained by the ex situ method, and (c) $\mathrm{MoS}_{2} / \mathrm{TiO}_{2} \mathrm{n}$-sh obtained by the in situ method.

Surprisingly, moving to the spectra of $\mathrm{CO}$ adsorbed on the surface of $\mathrm{MoS}_{2} / \mathrm{TiO}_{2}$ nanosheets obtained by ex situ approach (Figure $6 \mathrm{~b}$ ), no vibrational modes associated with molybdenum species are observed. The absorption bands are mainly due to the $\mathrm{CO}$ interaction with the support, which can be explained with the very low concentration of $\mathrm{Mo}^{\mathrm{x}+}$ species. However, a general decrease in intensity of the main IR features compared to pure $\mathrm{TiO}_{2} \mathrm{n}$-sh is noted. It is plausible to assume that a few $\mathrm{MoS}_{2}$ slabs cover small surface regions on both $\{001\}$ and $\{101\}$ faces. This causes a lower number of available $\mathrm{Ti}^{4+}$ sites to interact with $\mathrm{CO}$ probe molecules, hence a decreased intensity of the adsorption signals on (101) and (001) surfaces. Finally, from the CO spectra on $\mathrm{MoS}_{2} / \mathrm{TiO}_{2}$ nanosheets (Mo 3 wt.\%) obtained by the in situ approach (Figure 6c), significant changes can be ob- 
served. At higher frequencies, the features at 2179 and $2159 \mathrm{~cm}^{-1}$, already assigned on previous systems to CO molecules adsorbed on $\mathrm{Ti}^{4+}$ sites on (101) and (001) surfaces, respectively, are also observed, but with a different intensity ratio. Considering the asymmetry on the low frequency side of the band centered at $2159 \mathrm{~cm}^{-1}$, modes due to CO physisorption on heterogeneous surface sites, including residual $\mathrm{OH}$ groups and/or sulfur anions on the basal planes of crystalline $\mathrm{MoS}_{2}$ cannot be ruled out [55]. However, in the $2130-2050 \mathrm{~cm}^{-1}$ range, two significant bands, at 2117 and $2066 \mathrm{~cm}^{-1}$, are observed which are absent on the $\mathrm{MoS}_{2} / \mathrm{TiO}_{2} \mathrm{n}$-sh sample obtained by the ex situ method (Figure $6 \mathrm{~b}$ ). The appearance of these features, downshifted with respect to the CO free molecule $\left(2143 \mathrm{~cm}^{-1}\right)$, indicates the formation of surface sites characterized by $\pi$-backdonation character [56]. They have already been assigned [57] to carbonyl species anchored on a multiplicity of coordinatively unsaturated $\mathrm{Mo}^{\mathrm{x}+}$ centers $(\mathrm{x}<4)$ on highly defective situations $(\mathrm{Mo}-\mathrm{S})$ [48,58]. In particular, the band at $2117 \mathrm{~cm}^{-1}$ can be ascribed to the $\mathrm{Mo}^{\mathrm{x}+}$ species $(\mathrm{x}<4)$ located on defective sites (e.g., edges), while the $2066 \mathrm{~cm}^{-1}$ one could be due to the interaction of $\mathrm{CO}$ with $\mathrm{Mo}^{\mathrm{x}+}$ species $(x<4)$ located on highly coordinatively unsaturated (cus) sites such as corners [41]. Such bands are the last to disappear by outgassing and this is a further confirmation of the presence of isolated and cus molybdenum species on defective sites associated with the formation of sulfur vacancies [45].

FTIR spectra of $\mathrm{CO}$ adsorbed at $77 \mathrm{~K}$ at maximum coverage on $\mathrm{TiO}_{2} \mathrm{n}$-sh, $\mathrm{MoS}_{2} / \mathrm{TiO}_{2}$ n-sh (via ex situ method), and $\mathrm{MoS}_{2} / \mathrm{TiO}_{2} \mathrm{n}$-sh (via in situ method) are compared in Figure 7 (black, blue, and red curves, respectively) aiming to investigate the effects of the different synthesis methods on the surface properties of the two-system $\mathrm{MoS}_{2} / \mathrm{TiO}_{2}$ n-sh, as compared to the pure $\mathrm{TiO}_{2}$-nsh sample. First, it appears that (i) the spectra of both the $\mathrm{MoS}_{2} / \mathrm{TiO}_{2} \mathrm{n}$-sh samples are characterized by a lower intensity of the typical signals at 2179 and $2159 \mathrm{~cm}^{-1}$ due to the adsorption of CO on the (101) and (001) surfaces, respectively; and (ii) only for the $\mathrm{MoS}_{2} / \mathrm{TiO}_{2} \mathrm{n}$-sh sample prepared via the in situ method, the signals in the range $2130-2050 \mathrm{~cm}^{-1}$, associated with reduced $\mathrm{Mo}^{\mathrm{x}}$ species $(\mathrm{x}<4)$, are observed. The general decrease in intensity can be associated with the presence of new $\mathrm{Mo}^{\mathrm{x}}$ species masking the $\mathrm{Ti}^{4+}$ sites, which are no longer available for interactions with CO. Such a phenomenon is more evident on $\mathrm{MoS}_{2} / \mathrm{TiO}_{2} \mathrm{n}$-sh prepared via the in situ approach, due to the higher $\mathrm{MoS}_{2}$ concentration, than on the sample obtained via the ex situ method. Furthermore, the absence of the components assigned to $\mathrm{Mo}^{\mathrm{x}+}$ species in reduced states $(x<4)$ for the sample obtained by the ex situ method can be explained by the fact that the $\mathrm{Mo}^{\mathrm{x}+}$ species are present only on defective sites belonging to thin and uniformly distributed $\mathrm{MoS}_{2}$ slabs. Indeed, the HRTEM images (Figure 3) have shown thinner and more defective $\mathrm{MoS}_{2}$ slabs for the sample prepared by the in situ approach. Conversely, preparation via the ex situ approach gives rise to a heterogeneous and minor amount of $\mathrm{MoS}_{2}$ slabs anchored to the surface of $\mathrm{TiO}_{2}$ nanosheets, which are characterized by a higher level of stacking and are therefore less reactive. These remarks on different defects are in agreement with what has been observed with Raman (regarding the band at ca. $227 \mathrm{~cm}^{-1}$ ) and XRD analyses. 


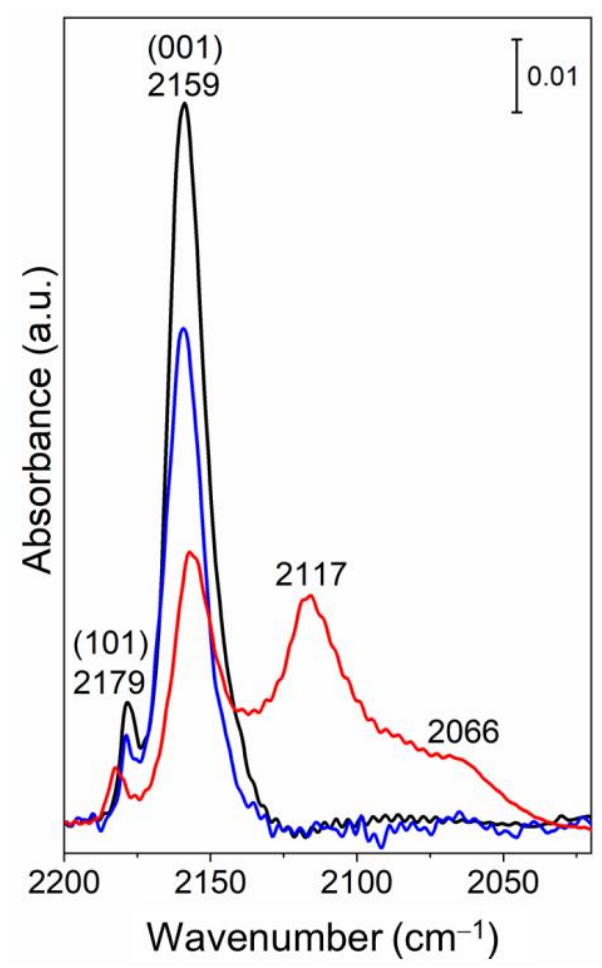

Figure 7. FTIR spectra, recorded at 77K, at the maximum coverage of $\mathrm{CO}$ (30 Torr) adsorbed on the surface of $\mathrm{TiO}_{2}$ anatase nanosheet (n-sh) pretreated at $873 \mathrm{~K}$ (black curve), of $\mathrm{MoS}_{2} / \mathrm{TiO}_{2} \mathrm{n}$-sh obtained by the ex situ method (blue curve), and of $\mathrm{MoS}_{2} / \mathrm{TiO}_{2} \mathrm{n}$-sh obtained by the in situ approach (red curve).

\section{Conclusions}

$\mathrm{MoS}_{2} / \mathrm{TiO}_{2}$ heterostructures, consisting of $\mathrm{MoS}_{2}$ slabs with different stacking order covering $\mathrm{TiO}_{2}$ nanosheets, have been synthesized following ex situ and in situ methods. Combining XRD, HRTEM, Raman, UV-visible, and FTIR data, the characteristics of $\mathrm{MoS}_{2} / \mathrm{TiO}_{2}$ heterostructures obtained from ex situ and in situ preparations were compared, highlighting the role played by the synthesis processes in affecting morphology, structure, stacking order, and defectivity. In more detail, $\mathrm{MoS}_{2}$ slabs as obtained by the in situ preparation appear to be thinner and more defective (i.e., basal plane interruptions, more curved structures decorating the anatase facets) with respect to the slabs obtained by the ex situ preparation, despite the higher $\mathrm{MoS}_{2}$ concentration.

In particular, the stacking number of $3 \pm 2$ layers and basal sizes of 2-10 nm for $\mathrm{MoS}_{2}$ particles on $\mathrm{MoS}_{2} / \mathrm{TiO}_{2}$ nanosheets coming from the in situ method could be estimated, whereas the stacking number $>5-6$ and lateral dimension of $20 \mathrm{~nm}$ for $\mathrm{MoS}_{2}$ particles on $\mathrm{MoS}_{2} / \mathrm{TiO}_{2}$ nanosheets obtained by the ex situ method can be found. From the HRTEM analysis of samples obtained by the in situ method, the presence of more curved $\mathrm{MoS}_{2}$ slabs decorating the boundaries of the anatase nanosheets means that a relevant grafting of $\mathrm{MoS}_{2}$ particles at the $\{001\}$ and $\{101\}$ anatase facelets occurs. From this, it comes out that that the sulfidation process affects the reactivity of the support matrix as well, which in turn plays a role in the $\mathrm{MoS}_{2}$ /support interaction. The low dimensionality of the $\mathrm{MoS}_{2}$ particles on $\mathrm{MoS}_{2} / \mathrm{TiO}_{2}$ nanosheets synthesized via the in situ approach with respect to those obtained by the ex situ method, already explained in terms of quantum size effects, has been additionally confirmed from the UV-vis results.

Lastly, from the FTIR spectra, the presence of new $\mathrm{Mo}^{\mathrm{x}+}$ species on defective sites, masking the $\mathrm{Ti}^{4+}$ sites, which are no longer available for interactions with $\mathrm{CO}$, is a further confirmation that $\mathrm{MoS}_{2}$ slabs are thinner, more defective, and uniformly distributed for the sample prepared by the in situ approach, whereas $\mathrm{MoS}_{2}$ slabs obtained via the ex situ 
approach are more heterogeneously dispersed with a higher level of stacking and then lower reactivity.

In conclusion, we state that the morphology and dispersion of hybrid composites can be tailored by designing suitable preparation and activation conditions, also considering the interface structure and then the charge control.

Author Contributions: D.S., F.C., T.V., and R.S. wrote and organized the manuscript; T.V., R.S. and F.P. performed experiments and characterizations; in particular, F.P. contributed to sample preparation; D.S., F.C. and G.M. provided a substantial contribution to the work; D.S. supervised the manuscript. All authors approved it for publication. All authors have read and agreed to the published version of the manuscript.

Funding: This work was supported by MIUR (Ministero dell'Istruzione, dell'Università e della Ricerca), INSTM Consorzio and NIS (Nanostructured Interfaces and Surfaces) Inter-Departmental Center of University of Torino.

Institutional Review Board Statement: Not applicable.

Informed Consent Statement: Not applicable.

Data Availability Statement: "MDPI Research Data Policies" at https:/ /www.mdpi.com/ethics.

Acknowledgments: The authors thank the Laboratory of the Chemistry Department and, in particular, Signorile, M., Damin, A., Bonino, F., Maurino, V., Cravanzola, S. and Valsania, M.C.

Conflicts of Interest: The authors declare no conflict of interest.

\section{References}

1. Chatterjee, D.; Mahata, A. Visible light induced photodegradation of organic pollutants on dye adsorbed $\mathrm{TiO}_{2}$ surface. J. Photochem. Photobiol. A Chem. 2002, 153, 199-204. [CrossRef]

2. Matos, J.; García, A.; Zhao, L.; Titirici, M.M. Solvothermal carbon-doped $\mathrm{TiO}_{2}$ photocatalyst for the enhanced methylene blue degradation under visible light. Appl. Catal. A Gen. 2010, 390, 175-182. [CrossRef]

3. Cheng, Y.; Geng, H.; Huang, X. Advanced water splitting electrocatalysts via the design of multicomponent heterostructures. Dalton Trans. 2020, 49, 2761-2765. [CrossRef] [PubMed]

4. Uddin, J.; Daramola, D.E.; Velasquez, E.; Dickens, T.J.; Yan, J.; Hammel, E.; Cesano, F.; Okoli, O.I. A high efficiency 3D photovoltaic microwire with carbon nanotubes (CNT)-quantum dot (QD) hybrid interface. Phys. Status solidi Rapid Res. Lett. 2014, 8, 898-903. [CrossRef]

5. Zhao, N.; Meng, Y.; Sha, J.; Zhong, C.; Yuhuan, M.; Zhao, N. Preparation of $\mathrm{MoS}_{2} / \mathrm{TiO}_{2}$ based nanocomposites for photocatalysis and rechargeable batteries: Progress, challenges, and perspective. Nanoscale 2018, 10, 34-68. [CrossRef]

6. Wang, H.; Liu, F.; Fu, W.; Fang, Z.; Zhou, W.; Liu, Z. Two-dimensional heterostructures: Fabrication, characterization, and application. Nanoscale 2014, 6, 12250-12272. [CrossRef]

7. Wang, Z.; Mi, B. Environmental Applications of 2D Molybdenum Disulfide $\left(\mathrm{MoS}_{2}\right)$ Nanosheets. Environ. Sci. Technol. 2017, 51, 8229-8244. [CrossRef]

8. Yuan, Y.-J.; Ye, Z.-J.; Lu, H.-W.; Hu, B.; Li, Y.-H.; Chen, D.-Q.; Zhong, J.-S.; Yu, Z.-T.; Zou, Z.-G. Constructing Anatase $\mathrm{TiO}_{2}$ Nanosheets with Exposed (001) Facets/Layered $\mathrm{MoS}_{2}$ Two-Dimensional Nanojunctions for Enhanced Solar Hydrogen Generation. ACS Catal. 2016, 6, 532-541. [CrossRef]

9. Goswami, N.; Giri, A.; Pal, S.K. $\mathrm{MoS}_{2}$ Nanocrystals Confined in a DNA Matrix Exhibiting Energy Transfer. Langmuir 2013, 29 , 11471-11478. [CrossRef]

10. Lee, Y.-H.; Zhang, X.; Zhang, W.; Chang, M.-T.; Lin, C.-T.; Chang, K.-D.; Yu, Y.-C.; Wang, J.T.-W.; Chang, C.-S.; Li, L.-J.; et al. Synthesis of Large-Area $\mathrm{MoS}_{2}$ Atomic Layers with Chemical Vapor Deposition. Adv. Mater. 2012, 24, 2320-2325. [CrossRef]

11. Stephenson, T.; Li, Z.; Olsen, B.C.; Mitlin, D. Lithium ion battery applications of molybdenum disulfide $\left(\mathrm{MoS}_{2}\right)$ nanocomposites. Energy Environ. Sci. 2014, 7, 209-231. [CrossRef]

12. Lin, Y.; Ren, P.; Wei, C. Fabrication of $\mathrm{MoS}_{2} / \mathrm{TiO}_{2}$ heterostructures with enhanced photocatalytic activity. CrystEngComm 2019, 21, 3439-3450. [CrossRef]

13. Wan, J.; Lacey, S.D.; Dai, J.; Bao, W.; Fuhrer, M.S.; Hu, L. Tuning two-dimensional nanomaterials by intercalation: Materials, properties and applications. Chem. Soc. Rev. 2016, 45, 6742-6765. [CrossRef]

14. Sreepal, V.; Yagmurcukardes, M.; Vasu, K.S.; Kelly, D.J; Taylor, S.F.R.; Kravets, V.G.; Kudrynskyi, Z.; Kovalyuk, Z.D.; Patanè, A.; Grigorenko, A.N.; et al. Two-Dimensional Covalent Crystals by Chemical Conversion of Thin van der Waals Materials. Nano Lett. 2019, 19, 6475-6481. [CrossRef] [PubMed]

15. Zhao, X.; Song, P.; Wang, C.; Riis-Jensen, A.C.; Fu, W.; Deng, Y.; Wan, D.; Kang, L.; Ning, S.; Dan, J.; et al. Engineering covalently bonded 2D layered materials by self-intercalation. Nat. Cell Biol. 2020, 581, 171-177. [CrossRef] [PubMed]

16. Geim, A.K.; Grigorieva, I.V. Van der Waals heterostructures. Nat. Cell Biol. 2013, 499, 419-425. [CrossRef] [PubMed] 
17. Pumera, M.; Loo, A.H. Layered transition-metal dichalcogenides $\left(\mathrm{MoS}_{2}\right.$ and $\left.\mathrm{WS}_{2}\right)$ for sensing and biosensing. TrAC Trends Anal. Chem. 2014, 61, 49-53. [CrossRef]

18. Guo, L.; Yang, Z.; Marcus, K.; Li, Z.; Luo, B.; Zhou, L.; Wang, X.; Du, Y.; Yang, Y. $\mathrm{MoS}_{2} / \mathrm{TiO}_{2}$ heterostructures as nonmetal plasmonic photocatalysts for highly efficient hydrogen evolution. Energy Environ. Sci. 2018, 11, 106-114. [CrossRef]

19. Scarano, D.; Cesano, F.; Zecchina, A. $\mathrm{MoS}_{2}$ Domains on $\mathrm{TiO}_{2}-$ Based Nanostructures: Role of Titanate/TiO 2 Transformation and Sulfur Doping on the Interaction with the Support. J. Phys. Chem. C 2019, 123, 7799-7809. [CrossRef]

20. Cravanzola, S.; Sarro, M.; Cesano, F.; Calza, P.; Scarano, D. Few-Layer $\mathrm{MoS}_{2}$ Nanodomains Decorating TiO 2 Nanoparticles: A Case Study for the Photodegradation of Carbamazepine. Nanomaterials 2018, 8, 207. [CrossRef]

21. Kumar, S.G.; Devi, L.G. Review on Modified $\mathrm{TiO}_{2}$ Photocatalysis under UV/Visible Light: Selected Results and Related Mechanisms on Interfacial Charge Carrier Transfer Dynamics. J. Phys. Chem. A 2011, 115, 13211-13241. [CrossRef]

22. Rao, C.; Maitra, U.; Waghmare, U.V. Extraordinary attributes of 2-dimensional $\mathrm{MoS}_{2}$ nanosheets. Chem. Phys. Lett. 2014, 609, 172-183. [CrossRef]

23. Zhou, X.; Dong, H. A Theoretical Perspective on Charge Separation and Transfer in Metal Oxide Photocatalysts for Water Splitting. Chem CatChem 2019, 11, 3688-3715. [CrossRef]

24. Selcuk, S.; Selloni, A. Surface Structure and Reactivity of Anatase $\mathrm{TiO}_{2}$ Crystals with Dominant $\{001\}$ Facets. J. Phys. Chem. C 2013, 117, 6358-6362. [CrossRef]

25. Yang, X.; Huang, H.; Jin, B.; Luo, J.; Zhou, X. Facile synthesis of $\mathrm{MoS}_{2} / \mathrm{B}-\mathrm{TiO}_{2}$ nanosheets with exposed $\{001\}$ facets and enhanced visible-light-driven photocatalytic $\mathrm{H} 2$ production activity. RSC Adv. 2016, 6, 107075-107080. [CrossRef]

26. Chen, H.; Wen, X.; Zhang, J.Z.G.; Wu, T.; Gong, Y.; Zhang, X.; Yuan, J.; Yi, C.; Lou, J.; Ajayan, P.M.; et al. Ultrafast formation of interlayer hot excitons in atomically thin $\mathrm{MoS}_{2} / \mathrm{WS}_{2}$ heterostructures. Nat. Commun. 2016, 7, 12512. [CrossRef]

27. Hu, X.; Lu, S.; Tian, J.; Wei, N.; Song, X.; Wang, X.; Cui, H. The selective deposition of $\mathrm{MoS}_{2}$ nanosheets onto (101) facets of $\mathrm{TiO}_{2}$ nanosheets with exposed (001) facets and their enhanced photocatalytic H2 production. Appl. Catal. B: Environ. 2019, 241, 329-337. [CrossRef]

28. Chen, C.; Xin, X.; Zhang, J.; Li, G.; Zhang, Y.; Lu, H.; Gao, J.; Yang, Z.; Wang, C.; He, Z. Few-Layered MoS 2 Nanoparticles Loaded $\mathrm{TiO}_{2}$ Nanosheets with Exposed \{001\} Facets for Enhanced Photocatalytic Activity. Nano 2018, 13, 1850129. [CrossRef]

29. Zhang, J.; Huang, L.; Lu, Z.; Jin, Z.; Wang, X.; Xu, G.; Zhang, E.; Wang, H.; Kong, Z.; Xi, J.; et al. Crystal face regulating MoS $2 /$ TiO $_{2}$ (001) heterostructure for high photocatalytic activity. J. Alloy. Compd. 2016, 688, 840-848. [CrossRef]

30. Cao, L.; Wang, R.; Wang, N.; Li, X.; Jia, H. $\mathrm{MoS}_{2}$-hybridized $\mathrm{TiO}_{2}$ nanosheets with exposed $\{001\}$ facets to enhance the visible-light photocatalytic activity. Mater. Lett. 2015, 160, 286-290. [CrossRef]

31. Wei, T.; Lau, W.-M.; An, X.; Liu, J. Interfacial Charge Transfer in $\mathrm{MoS}_{2} / \mathrm{TiO}_{2}$ Heterostructured Photocatalysts: The Impact of Crystal Facets and Defects. Molecules 2019, 24, 1769. [CrossRef]

32. Dozzi, M.V.; Selli, E. Specific Facets-Dominated Anatase $\mathrm{TiO}_{2}$ : Fluorine-Mediated Synthesis and Photoactivity. Catalysts 2013, 3 , 455-485. [CrossRef]

33. Gordon, T.R.; Cargnello, M.; Paik, T.; Mangolini, F.; Weber, R.T.; Fornasiero, P.; Murray, C.B. Nonaqueous Synthesis of TiO 2 Nanocrystals Using TiF4 to Engineer Morphology, Oxygen Vacancy Concentration, and Photocatalytic Activity. J. Am. Chem. Soc. 2012, 134, 6751-6761. [CrossRef] [PubMed]

34. Uddin, J.; Cesano, F.; Chowdhury, A.R.; Trad, T.; Cravanzola, S.; Martra, G.; Mino, L.; Zecchina, A.; Scarano, D. Surface Structure and Phase Composition of $\mathrm{TiO}_{2}$ P25 Particles After Thermal Treatments and HF Etching. Front. Mater. 2020, 7, 192. [CrossRef]

35. Mino, L.; Pellegrino, F.; Rades, S.; Radnik, J.; Hodoroaba, V.-D.; Spoto, G.; Maurino, V.; Martra, G. Beyond Shape Engineering of $\mathrm{TiO}_{2}$ Nanoparticles: Post-Synthesis Treatment Dependence of Surface Hydration, Hydroxylation, Lewis Acidity and Photocatalytic Activity of $\mathrm{TiO}_{2}$ Anatase Nanoparticles with Dominant $\{001\}$ or $\{101\}$ Facets. ACS Appl. Nano Mater. 2018, 1, $5355-5365$. [CrossRef]

36. Davydov, A. Theoretical Fundamentals and Experimental Considerations of the Spectroscopic Methods Used in Surface Chemistry; Wiley: Chichester, UK, 2003; pp. 1-25.

37. Pellegrino, F.; Sordello, F.; Mino, L.; Minero, C.; Hodoroaba, V.-D.; Martra, G.; Maurino, V. Formic Acid Photoreforming for Hydrogen Production on Shape-Controlled Anatase $\mathrm{TiO}_{2}$ Nanoparticles: Assessment of the Role of Fluorides, $\{101\} /\{001\}$ Surfaces Ratio, and Platinization. ACS Catal. 2019, 9, 6692-6697. [CrossRef]

38. Han, X.; Kuang, Q.; Jin, M.; Xie, Z.; Zheng, L. Synthesis of Titania Nanosheets with a High Percentage of Exposed (001) Facets and Related Photocatalytic Properties. J. Am. Chem. Soc. 2009, 131, 3152-3153. [CrossRef]

39. Zhang, Y.; Cai, J.; Ma, Y.; Qi, L. Mesocrystalline $\mathrm{TiO}_{2}$ nanosheet arrays with exposed $\{001\}$ facets: Synthesis via topotactic transformation and applications in dye-sensitized solar cells. Nano Res. 2017, 10, 2610-2625. [CrossRef]

40. Muscuso, L.; Cravanzola, S.; Cesano, F.; Scarano, D.; Zecchina, A. Optical, Vibrational, and Structural Properties of MoS 2 Nanoparticles Obtained by Exfoliation and Fragmentation via Ultrasound Cavitation in Isopropyl Alcohol. J. Phys. Chem. C 2015, 119, 3791-3801. [CrossRef]

41. Cesano, F.; Bertarione, S.; Piovano, A.; Agostini, G.; Rahman, M.M.; Groppo, E.; Bonino, F.; Scarano, D.; Lamberti, C.; Bordiga, S.; et al. Model oxide supported $\mathrm{MoS}_{2}$ HDS catalysts: Structure and surface properties. Catal. Sci. Technol. 2011, 1, 123-136. [CrossRef]

42. Cravanzola, S.; Cesano, F.; Magnacca, G.; Zecchina, A.; Scarano, D. Designing rGO/MoS ${ }_{2}$ hybrid nanostructures for photocatalytic applications. RSC Adv. 2016, 6, 59001-59008. [CrossRef] 
43. Cesano, F.; Agostini, G.; Scarano, D. Nanocrystalline $\mathrm{TiO}_{2}$ micropillar arrays grafted on conductive glass supports: Microscopic and spectroscopic studies. Thin Solid Film. 2015, 590, 200-206. [CrossRef]

44. Sharma, A.A.; Mahlouji, R.; Wu, L.; Verheijen, M.A.; Vandalon, V.; Balasubramanyam, S.; Hofmann, J.P.; Kessels, W.M.M.; Bol, A.A. Large area, patterned growth of $2 \mathrm{D} \mathrm{MoS}_{2}$ and lateral $\mathrm{MoS}_{2}-\mathrm{WS}_{2}$ heterostructures for nano- and opto-electronic applications. Nanotechnology 2020, 31, 255603. [CrossRef]

45. Cravanzola, S.; Cesano, F.; Gaziano, F.; Scarano, D. Sulfur-Doped $\mathrm{TiO}_{2}$ : Structure and Surface Properties. Catalysts 2017, 7, 214. [CrossRef]

46. Kumar, S.; Shakya, J.; Mohanty, T. Probing interfacial charge transfer dynamics in $\mathrm{MoS}_{2} / \mathrm{TiO}_{2}$ nanocomposites using scanning Kelvin probe for improved photocatalytic response. Surf. Sci. 2020, 693, 121530. [CrossRef]

47. Mignuzzi, S.; Pollard, A.J.; Bonini, N.; Brennan, B.; Gilmore, I.S.; Pimenta, M.A.; Richards, D.; Roy, D. Effect of disorder on Raman scattering of single-layer $\mathrm{MoS}_{2}$. Phys. Rev. B 2015, 91. [CrossRef]

48. Cravanzola, S.; Cesano, F.; Gaziano, F.; Scarano, D. Carbon Domains on $\mathrm{MoS}_{2} / \mathrm{TiO}_{2}$ System via Catalytic Acetylene Oligomerization: Synthesis, Structure, and Surface Properties. Front. Chem. 2017, 5, 91. [CrossRef] [PubMed]

49. Lee, C.; Yan, H.; Brus, L.E.; Heinz, T.F.; Hone, J.; Ryu, S. Anomalous Lattice Vibrations of Single- and Few-Layer MoS 2 . ACS Nano 2010, 4, 2695-2700. [CrossRef]

50. Li, H.; Zhang, Q.; Yap, C.C.R.; Tay, B.K.; Edwin, T.H.T.; Olivier, A.; Baillargeat, D. From Bulk to Monolayer MoS 2 : Evolution of Raman Scattering. Adv. Funct. Mater. 2012, 22, 1385-1390. [CrossRef]

51. Wilcoxon, J.P.; Newcomer, P.P.; Samara, G.A. Synthesis and optical properties of $\mathrm{MoS}_{2}$ and isomorphous nanoclusters in the quantum confinement regime. J. Appl. Phys. 1997, 81, 7934-7944. [CrossRef]

52. Cravanzola, S.; Muscuso, L.; Cesano, F.; Agostini, G.; Damin, A.; Scarano, D.; Zecchina, A. MoS ${ }_{2}$ Nanoparticles Decorating Titanate-Nanotube Surfaces: Combined Microscopy, Spectroscopy, and Catalytic Studies. Langmuir 2015, 31, 5469-5478. [CrossRef] [PubMed]

53. Matte, H.S.S.R.; Gomathi, A.; Manna, A.K.; Late, D.J.; Datta, R.; Pati, S.K.; Rao, C.N.R. $\mathrm{MoS}_{2}$ and WS 2 Analogues of Graphene. Angew. Chem. Int. Ed. 2010, 49, 4059-4062. [CrossRef]

54. Shi, H.; Yan, R.; Bertolazzi, S.; Brivio, J.; Gao, B.; Kis, A.; Jena, D.; Xing, H.G.; Huang, L. Exciton Dynamics in Suspended Monolayer and Few-Layer $\mathrm{MoS}_{2}$ 2D Crystals. ACS Nano 2013, 7, 1072-1080. [CrossRef] [PubMed]

55. Tsyganenko, A.A.; Can, F.; Travert, A.; Maugé, F. FTIR study of unsupported molybdenum sulfide?in situ synthesis and surface properties characterization. Appl. Catal. A Gen. 2004, 268, 189-197. [CrossRef]

56. Bolis, V.; Barbaglia, A.; Bordiga, S.; Lamberti, A.C.; Zecchina, A. Heterogeneous Nonclassical Carbonyls Stabilized in Cu(I) - and Ag(I)-ZSM-5 Zeolites: Thermodynamic and Spectroscopic Features. J. Phys. Chem. B 2004, 108, 9970-9983. [CrossRef]

57. Bachelier, J.; Duchet, J.; Cornet, D. On the promoting effect in sulfided Ni\$z.sbnd;Mo/Al2O3 catalysts as studied by chemisorption. J. Catal. 1984, 87, 283-291. [CrossRef]

58. Maugé, F.; LaMotte, J.; Nesterenko, N.; Manoilova, O.; Tsyganenko, A. FT-IR study of surface properties of unsupported MoS 2 . Catal. Today 2001, 70, 271-284. [CrossRef] 